\title{
UNA MIRADA A LA SOLTERÍA MASCULINA
}

\section{A LOOK INTO THE MASCULINE BACHELORHOOD}

\author{
Argelia Gómez Ávilal \\ argelia_gom@prodigy.net.mx \\ Alejandra Salguero Velázquez ${ }^{2}$ \\ alevs@unam.mx
}

Fecha de recepción: 23 mayo 2013 - Fecha de aceptación: 9 enero 2014

\begin{abstract}
Resumen
Históricamente se ha centrado la mirada social y académica sobre la condición de soltería en las mujeres más que en la de los varones, lo cual se ha reflejado en la escasa investigación acerca de la soltería de éstos. A su vez este artículo presenta un análisis sobre las razones de la condición de soltería que dan los hombres profesionistas de nivel socio-económico medio del Estado de México. Se llevó a cabo una investigación cualitativa, realizando entrevistas semiestructuradas con siete participantes entre 32 y 49 años de edad. Los datos muestran que entre las razones para continuar solteros están: la defensa de la libertad, la renuencia a la proveeduría por la corresponsabilidad económica, y el impacto de los rechazos amorosos. Continúa en discusión si se están construyendo nuevas formas de "ser hombre", si éstas pueden generar cambios a favor de ambos géneros, o es una soltería basada en estereotipos tradicionales con tintes modernos.

Palabras claves: Soltería, masculinidad, pareja, compromiso, género.
\end{abstract}

\begin{abstract}
Historically society has placed more attention on the unmarried woman as opposed to the unmarried male, which is reflected in the lack of research on male bachelorhood. This paper presents an analysis of the reason that gives professional men of medium socioeconomic level of Mexico about his singleness. We conducted a qualitative research, with semistructured interviews in seven participants between 32 and 49 years old. The data show that among the reasons to continue bachelor identifies three central arguments: the defense of freedom, the refusal to be economical provider, and the impact of loving rejections. Continued discussion if they are building new ways of being a man, if they can generate changes for the benefit of both genders, or his singleness be based on traditional stereotypes with modern dyes Keywords: Singleness, masculinity, couple, commitment, gender.
\end{abstract}

1 Doctoranda del posgrado de Psicología. UNAM, profesora del sistema SUAYED Iztacala.

2 Profesora Titular de la Carrera de Psicología en la FES Iztacala, UNAM. 


\section{Introducción}

Es notoria la diferencia en el número de publicaciones sobre soltería femenina y masculina. En relación con la primera, se ha indagado el autoconcepto en mujeres solteras (Gigy, 1980), la soltería y la vejez (Baumbusch, 2004), su estilo de vida, y el estigma social (Situmorang, 2007).

La investigación sobre la soltería masculina, se ha enfocado, esencialmente, en los estereotipos y estigma de los solteros en comparación con hombres viudos y divorciados. A los solteros generalmente se les atribuyen prácticas de promiscuidad e inestabilidad, sin embargo, dichos planteamientos se basan en estereotipos que en ocasiones no coinciden con las diversas realidades sociales. Guevara (2010), considera que la vida amorosa de los hombres con pareja y sin ella son tópicos, pocos explorados académicamente. Esto nos lleva a la necesidad de reflexionar y continuar investigando sobre la soltería masculina, pues los hombres son poco interrogados sobre sus razones y la vivencia de su condición.

\section{Discursos sociales sobre la soltería masculina}

En general, la soltería puede ser considerada bajo dos dimensiones: la legal, que es el estado civil de no casado, y la social, que hace referencia a una persona que no tiene una pareja reconocida social y jurídicamente.

Según el diccionario de Moliner (2001), la palabra soltero se deriva del latín solittariu, que significa "no estar casado", dalaga, mancebo, mozo, solterón, quedarse para vestir imágenes. Así pues, algunos de los adjetivos de esta definición suelen asociarse más a la soltería femenina, en tanto que la soltería masculina se percibe como un estado de disfrute para conocer y tener experiencias sexuales, afectivas o emocionales sin perder la libertad, así como lo reflejan los refranes: "sigamos solteros, que con las casadas nos acompañaremos", "él que era soltero y se casó, diga que vino el diablo y se lo llevó" o "la soledad del hombre es una aventura, la de la mujer una maldición" (Fernández, 2004).

Pese a esta imagen de sarcasmo ante la soltería masculina, no todos los hombres lo ven de igual manera, pues algunos expresan el deseo de formar y hacer vida en pareja; por ello se ha generado literatura con diversas posturas que reflejan discursos sociales, que van desde promover y defender la soltería masculina mostrando sus ventajas, hasta quienes consideran que es un estado de desadaptación social y/o psicológica.

Además dentro de la literatura de autoayuda, se encuentra Lenard (2007), quien defiende y justifica la soltería, en su libro ¿Cazado..? ¡Mejor solterón!, reivindica a los solteros señalando que deciden rehuir al compromiso para mantener su individualidad, su libertad para salir y cambiar de pareja; que han dejado de ver el matrimonio como un estado de realización personal, equilibrio y madurez emocional. Del mismo modo desmitifica que ser soltero sea signo de soledad, que el matrimonio sea igual a felicidad, que los solteros son personas amargadas, y afirma que se ven más perjudicados cuando se comprometen, pues el vínculo amor-matrimoniomonogamia genera desventajas.

Sin embargo, un planteamiento contrario es el de Gilder (1974), quien en su libro Naked nomads, describe a los solteros como hombres socialmente inadaptados, inestables, propensos a las adicciones, a las enfermedades, sin raíces y poco orientados al futuro y una de las críticas a este texto es su generalización, pues contribuye a perpetuar el estigma social. Se suma a esta línea, el trabajo de Hunter (2012), en su libro Los secretos de los hombres solteros en el cual no sólo analiza las causas por las que los hombres no se comprometen en una relación de pareja, sino que invita a las mujeres, a que identifiquen esos comportamientos y puedan hacer desistir a los hombres de permanecer en soltería.

Por lo tanto, estos discursos sociales, se llevan al quehacer científico para indagar y documentar de manera sistemática la condición de soltería. Dentro del campo de la sociología y psicología encontramos estudios tales como: "Celibato masculino" (Bourdieu, 2004), "La psicología del soltero" (Bernand, 2004), "Prácticas reproductivas de solteras y solteros" (Tena, 2002). De acuerdo con esto Tena (2002) encontró que hombres mayores de treinta años, solteros, sin hijos, mostraban una tendencia a relacionarse con mujeres más jóvenes, posponían la formación de la pareja por temor a repetir patrones vividos en 
la relación con sus padres, o porque reconocían en ellos algunas características que dificultarían una relación de pareja satisfactoria -como el hecho de saberse infieles-, además de valorar la continuidad de su libertad e independencia económica. Por su parte, los resultados de la investigación de López (2007) con varones mexicanos, muestran que entre las ventajas reportadas por sus participantes con respecto a su soltería, se encuentran el tener tiempo libre, no tener que rendir cuentas a nadie, la disposición de su dinero, libertad para divertirse, conocer personas y tener relaciones superficiales, así como la posibilidad para destinar tiempo, esfuerzo y dinero para prepararse académicamente y lograr un desarrollo profesional. También manifestaron sentirse felices por su estilo de vida, sin embargo resaltaron que en el futuro les gustaría formar una familia.

De manera similar, Carmona y Farías (2008), encontraron que los solteros le dan prioridad a su proyección laboral y profesional; un dato interesante es que experimentan miedo de encontrar una pareja y perder su bienestar, y contradictoriamente desean que ésta llegue en algún momento de su vida y formalicen la relación en matrimonio. De este modo, las investigaciones de Tena (2002), López (2007) Carmona y Farías (2008), se consideran un buen referente sobre los solteros mexicanos.

Además, en España, Argentina, Estados Unidos y Uruguay, se ha encontrado que los varones solteros expresan aversión a depender de una relación, disfrutan de su independencia y no están preocupados por la postergación de la familia; saben que en ellos no recae la presión social de tener que cumplir con la conyugalidad y la paternidad (Brando, 2009). Así pues, una manera de abordar la condición de soltería es a través de la perspectiva de género y el estudio de las masculinidades.

\section{Masculinidad y soltería}

El planteamiento central es que históricamente ha habido discursos y prácticas sociales que colocan a los géneros en condiciones de desventaja social a partir de un orden socioculturalhistórico donde la norma es la conyugalidad, la maternidad/paternidad, la cual "se debe cumplir" en un momento determinado en la trayectoria de vida. Martínez y Bonilla (2000), destacan que desde esta perspectiva, se pueden analizar algunos mecanismos de valoración que marcan distinciones como ser soltero/a versus casado/a. Estas valoraciones se ven vinculadas a la edad de la soltería, pues para los jóvenes solteros se considera perfectamente aceptable, mientras que las personas que rebasan los 40 años, son vistas como que "ya ha pasado su mejor momento" o que "han fracasado"(Morris; De Paulo; Hertel \& Ritter, 2004 citados en Byrne, Carr, 2005).

Por un lado, estar casado elevaba el rango social, y para muchos, aún a la fecha, entre más capaz y exitoso se muestra un varón, se vuelve más atractivo para el matrimonio, a partir del cual obtiene su estatus de jefe de familia, pues representa que es capaz de tener a su cargo el cuidado y manutención de una mujer y de hijos, es decir, se puede hacer cargo de otros, contribuyendo a mantener y mejorar su imagen y desarrollo como "hombre", adquiriendo reconocimiento social por su capacidad de proveer y procrear para mantener el orden "natural" y los mandatos de la masculinidad hegemónica. Por lo tanto, el varón joven y soltero, que por este sólo hecho ya goza de importancia en la sociedad, cuando cumple con la conyugalidad, reafirma e incrementa su valía en relación con su familia (esposa e hijos) porque se convierte en jefe de un hogar y posee la autoridad en el grupo familiar, con respaldo legal y social (Olavarría, 2001).

Por otro lado, a partir del orden sociocultural-histórico en el cual la norma es la conyugalidad, el discurso social plantea que existen ganancias de género para los hombres, tales como: estatus social (es el jefe de familia, es un hombre maduro y responsable); beneficios en cuanto a la organización de la vida familiar al tener asegurada la alimentación, cuidado, organización y limpieza del hogar, la atención de los hijos o familiares dependientes (tareas que recaen generalmente en las mujeres); obtención de créditos mancomunados, entre otras.

Con base en lo anterior, surgen algunos cuestionamientos: ¿por qué permanecen solteros los hombres mayores de 30 años, y cuáles serían las razones?, ¿por qué algunos postergan las ganancias de género otorgadas por la 
conyugalidad?, ¿considerarán que la relación de pareja los atrapa y coacciona su libertad?.

Por lo tanto, se plantea como objetivo del presente trabajo, identificar los argumentos que muestran los hombres solteros profesionistas de nivel socioeconómico medio, sobre su condición de soltería.

\section{Desarrollo}

Los datos se derivan de una investigación de corte cualitativo descriptivo. De acuerdo con Ruiz (1999), esta metodología parte del supuesto básico de que el mundo social está construido por significados y símbolos. El interés se centra en la búsqueda de los significados y construcciones sociales desde el punto de vista de los protagonistas.

Los datos incorporan entrevistas semiestructuradas con siete varones solteros entre 34 y 49 años de edad, llevadas a cabo durante el periodo de septiembre-diciembre de 2011. Con esto, se definió como persona soltera el no haber contraído matrimonio civil ni religioso, ni haber tenido experiencia de cohabitación, ni haber tenido hijos. Todos los participantes son profesionistas, cuatro de ellos ingenieros, un periodista, un psicólogo, y un pasante de la licenciatura en informática. Sus ingresos económicos son superiores a cinco salarios mínimos y sólo uno de ellos se encuentra en un trabajo informal. Tres viven en la casa familiar. Sólo dos de ellos reportaron tener pareja estable en el momento de la entrevista, sin planes para formalizar, habitan en el Estado de México y pertenecen al nivel socioeconómico medio. De acuerdo con Blanco (1999), este estrato comprende hogares de trabajadores asalariados (empleados, oficinistas y trabajadores por cuenta propia) en consecuencia, en este nivel socioeconómico se expresa con mayor nitidez el impacto de los cambios culturales de las últimas décadas, y la concepción hegemónica del "éxito" juega un papel importante, pues actualmente muchos varones consideran que no alcanzan el éxito y el poder aún teniendo una carrera profesional (Salguero, 2008).

En la presente investigación se consideró como eje central de las entrevistas, la vivencia y el significado de la condición de soltería, puntualizando en las razones que facilitaban los varones; contemplándose en todo momento los aspectos éticos (información, confidencialidad $\mathrm{y}$ anonimato).

El manejo de datos se hizo a través de un análisis de contenido cualitativo que ha de entenderse como un metatexto, resultado de la transformación de un texto básico (o conjunto de ellos) de acuerdo a las reglas de procedimiento y análisis; mismas que permiten dividir el material en unidades más interpretables y obtener categorías centrales (Ruiz, 1999). Del mismo modo, se identificaron los siguientes cuatro temas: la casa familiar, relación de pareja, vivencia de la sexualidad y trabajo. De estos grandes temas, se derivaron las siguientes categorías de análisis: la defensa de la libertad, la renuencia a la proveeduría por la corresponsabilidad económica, y el impacto de los rechazos amorosos.

\section{La defensa de la libertad}

Algunos de los hombres entrevistados hicieron énfasis en la libertad, lo cual no implicaba estar sin pareja, como lo muestra el siguiente relato:

Me gustan las mujeres, y más bien he mantenido una lealtad al no asumirme con una mujer, cuando sé que yo puedo tener interés por otra $[\ldots]$ me gusta vincularme amorosamente, me gusta amar, y cuando tengo una relación estable me siento acotado siento que pierdo mi libertad. (Artemio)

El relato de Artemio, pone en evidencia uno de los rasgos de la masculinidad tradicional, "es fácil que los hombres se interesen por varias mujeres", "se enamoran con facilidad", es difícil ser leal (entiéndase como fiel) (Olavarría, 2001). Desde la perspectiva de Artemio, una relación estable lo acota, lo limita, prefiere la libertad y a su vez este argumento, coincide con el planteamiento de Raúl:

Soy muy individualista, siento que no debo atarme a nadie para poder hacer lo que yo quiera, entonces cuando estás en pareja, de cierta manera tienes que ceder ¿no?, hay que llegar a acuerdos y yo a veces no estoy muy a gusto con ese tipo de cosas porque siento que me limitan en mi manera de ser y en lo que yo quiero hacer...[...] En mi caso, yo rehuyo totalmente al compromiso emocional, mantengo mi individualidad, mi libertad, mi egoísmo. (Raúl). 
Ciertamente, el compromiso para estos varones significa atarse, ceder, limitarse en su manera de ser y hacer. Lenard (2007), señala que muchos hombres deciden rehuir al compromiso para mantener su individualidad y su libertad, pues son ganancias que pierden cuando se comprometen.

Por un lado, para Valcuende del Rio y Blanco (2004); Rhodes y Potash (1989), los varones aprenden que la condición masculina va íntimamente ligada con la noción de libertad, puesto que, han sido socializados para ser libres, $\mathrm{y}$ este es el fundamento de su capacidad de experimentar, conocer y autoconstruirse (Abarca, 1999). Este aprendizaje se traduce en cierta permisividad -para poder hacer lo que quieran-, imaginando que pueden devorar el mundo, el cual se toma para sí, y desde la perspectiva de los entrevistados, significa coartar la libertad, perder ese mundo al que por el sólo hecho de ser hombre 'han tenido derecho', han sido socializados en la lógica del individualismo, orientados a mostrarse fuertes, y que no dependen de un otro (Luco, 2001).

Por otro lado, para Guevara (2010), una relación pone a prueba su capacidad para conciliar sus intereses con los de su pareja y empatar además sus tiempos con los de ella; además se les dificulta leer lo que significa para ellas el matrimonio o la maternidad. En el siguiente relato vemos como Gustavo concibe que es él quien decide sobre la legalización del vínculo de pareja, parece predominar la racionalidad y la poca posibilidad de negociar:

Mi abuela siempre que me ve me pregunta que '¿cuándo me voy a casar?', como convivo más con la familia de mi novia... pues ya dan como establecido que yo ya me quedé ahí, y yo siempre les digo 'que lo estoy pensando' [...]lo he postergado, por distintas razones, yo le he manejado cuestiones como: 'que ella no está titulada y no quiero que sea un pretexto, que me diga que no se tituló porque se casó conmigo, y también el hecho de que tiene muchos problemas en su casa, no quiero que crea que es una solución casarnos y que así se va a solucionar todo', yo creo que es porque ella ya quiere ser mamá, entonces, le he manejado que tiene que resolver primero sus problemas. (Gustavo)

Salguero (2008), explica que gran parte del tiempo en la vida de los hombres está dedicado al trabajo, demeritando el tiempo ofrecido a la pareja y que la percepción de que tienen control sobre su vida, en muchas ocasiones, obstaculiza que no tomen en cuenta a las personas con las que se relacionan, como es la pareja, donde la decisión de formalizar depende de que ellos se convenzan.

Así pues, la defensa de la libertad es una de las razones más consistentes (Tena, 2002; Lenard, 2007; Carmona y Farías, 2008 y Brando, 2009). No obstante, para otro de los participantes, la libertad se gana al estar en pareja:

Yo creo que eso de que tienes libertad, es cierto, pero es temporal, no siempre quieres andar solo, creo que cuando tienes una compañera disfrutas la libertad, pues uno ya es libre, nadie nos tiene atados, puedes hacer muchas cosas con ella y otras solo, se trata de comunicarse como pareja. (Franco)

El planteamiento de Franco revela dos aspectos importantes, estar solo no es un estado siempre deseable como se ha manejado dentro de la masculinidad hegemónica, en algunos hay deseo de establecer una relación de pareja. Y en muchos varones hay un supuesto de que la pareja quita libertad, dificultando la posibilidad de construir formas distintas de relación de pareja donde se disfrute de manera conjunta la libertad.

\section{La renuencia a la proveeduría por la corresponsabilidad económica}

Raúl refirió que una de las razones por las que él u otros varones permanecen solteros, es que ahora es mucho más difícil mantener económicamente a alguien, por lo que ambos integrantes de la pareja tienen que trabajar:

"Somos una generación distinta a la de nuestros padres. En
cuanto a la cuestión económica, es mucho más difícil mante-
ner a alguien. Si estas en pareja, los dos tienen que trabajar,
ya no es como antes, que el proveedor tenía que trabajar,
llegaba en la noche y la esposa le tenía la cena servidita al
patrón. Ahora se opta por evitar esos problemas, algunos
se esperan a estar más estables, tener un buen ahorro, tener
primero su casa, sus bienes y disfrutarlos. (Raúl)

Raúl reconoce que es una generación distinta a la de sus padres, cuestiona el modelo tradicional del varón como único proveedor y la mujer como ama de casa. Hoy prefiere una 
relación que se caracterice por la co-responsabilidad en el gasto familiar.

Por su parte, la masculinidad hegemónica plantea el mandato de que un "verdadero" hombre es aquel que cumple con la proveeduría, sin embargo, ya no es un referente para algunos de los entrevistados. Hoy lo económico adquiere otra dimensión en un contexto de crisis económica en la cual se visualiza a la pareja como co-partícipe, no sólo en la administración de los recursos sino en su aportación.

Para algunos varones la renuencia a la proveeduría se relaciona con la percepción de que la principal causa de los conflictos en la pareja son los problemas económicos:

De niño... vives cosas, ves cosas, de cómo no funciona. Yo crecí con la idea de que la familia es una farsa [...] en los tíos ves conflictos, peleas, pero sobretodo muchos problemas económicos. (Raúl)

Hay parejas que se casan, luego hay pleitos por los gastos económicos.[...] a mí sí me gustaría casarme y tener mis hijos y todo[...] ¿por qué diría que no lo he hecho? pues a veces como que la piensas, porque dices ha de ser muy difícil. (Josué)

Además de la renuencia de continuar con el modelo de proveedor, está la apreciación de que los problemas de pareja y familiares generalmente se derivan de una economía precaria. Un hombre debe tener una estabilidad económica, trabajar arduamente para hacer un patrimonio, poseer un buen ahorro, esto desde los estereotipos de los roles tradicionales. El recurso monetario, constituía una condición que posibilitaba o no la decisión de vivir en pareja, considerando que los varones tenían que cumplir con su rol de proveedores (Tena, 2002). Sin embargo, hoy se piensa en los riesgos y angustias de vivir en pareja. El compromiso y la formalización se considera más en términos de costos y beneficios, en un contexto de movilidad social y geográfica, con mayor esperanza de vida, con la expansión de los sistemas educativos y la exigencia de adquirirlos (Bauman, 2001) tal como lo refleja el relato de Gustavo:

Una vez casado, pues cada quien con su vida profesional, con su trabajo, incluso con sus amistades laborales [...] pues sí, yo ya tengo mi casa, a lo mejor es algo envidioso, pero pues quiero que sea para mí y que sí queremos compartir, a lo mejor, sí buscar otra vivienda, yo quisiera que cada quien tuviera su propio espacio, que ella tuviera su casa y sus cosas, tal vez no tanto porque llegue un divorcio, pero si se da, cada quien por su lado, que cada quien tenga su propia casa y que no sea motivo de pelea el hecho de que se compró juntos y que hay que dividirnos los bienes. (Gustavo)

Vivir en pareja y compartir los gastos son tareas que sitúan a las posibles parejas femeninas en un determinado perfil, que es al que aspiran los varones: mujeres independientes, profesionistas, co-participes en la economía, comprensivas, automotivadas, que deseen tener hijos, entre otros:

No me veo siendo el mero proveedor, cuando salgo con compañeros nos repartimos los gastos, con mi pareja no es así, yo soy él que tiene que hacer el gasto [...] quiero una mujer independiente y profesionista, que tengamos hijos, que le guste superarse, que seamos críticos. Me han gustado las mujeres que tienen iniciativa, carácter, seguridad en sí mismas. (Artemio)

Con esto, la renuencia a la proveeduría forma parte de las transformaciones de algunos aspectos de las ganancias de género que ofrecía la conyugalidad. Anteriormente, la proveeduría otorgaba estatus al varón, pues al cumplir su papel se convertía en todo un "hombre". En los relatos de los entrevistados, se observa que es un rol que no les interesa cumplir, ellos prefieren establecer relaciones de pareja en las que ambos participen y se responsabilicen de la economía.

\section{El impacto de los rechazos amorosos}

Algunos entrevistados narraron situaciones de rupturas amorosas que tuvieron un impacto en su vida, influyendo en su condición de soltería. Las experiencias de rechazo se dieron en dos momentos. El primero, en la fase de cortejo y pretensión al noviazgo y el segundo, cuando querían formalizar la relación y vivir en pareja.

Alguna vez lo propuse (vivir en pareja); sin embargo, no se dio, ella me rechazó porque dice que yo me tardé, y que cuando se lo propuse, me vio dubitativo y cambio de decisión. (Artemio)

Conquistar a una mujer es una de las primeras pruebas que debe cumplir un varón para reconocerse y ser reconocido como hombre. Esta es una tarea aparentemente fácil, pero como 
señala Olavarría (2001), su ejercicio dependerá de los recursos que posean, del contexto social en el que viven, entre otras condiciones.

Lo he propuesto en dos casos, cuando era mucho más joven, recién salido de la universidad, me enamoré mucho, hubo un plan de vivir juntos, pero era más un deseo que un plan porque no había dinero, no había dónde irnos, uno anda muy adolescente muy juvenil, entonces nunca se concretó y ya más recientemente de unos 4, 5 años para acá le propuse a una chava que si éramos pareja, pero ella no quiso, ahí fue al revés, y bueno dejé de abordar el tema.[...] ahora que ya no pienso en eso, la ventaja es andar con chavas muy jóvenes, pues ellas, no están pensando en casarse ni en ser mamás, sino al contrario, quiere vivir más. (Raúl)

He experimentado rechazos (risas) 5 o 6 en mi vida (risas) y me dicen lo típico 'te prefiero como amigo, o no quiero que te pase como a mí, mejor no'.(Joel)

Lo velado en estos relatos es la emoción derivada del rechazo: el dolor que representa la confrontación como hombres socializados en un modelo hegemónico que los sitúa como varones "seguros, independientes, controlados y que tardan en comprometerse" y que cuando deciden hacerlo, exponen su virilidad, sus emociones de amor, deseo y compromiso, las cuales se ven rechazadas. En el caso de Raúl, la reacción fue encerrarse en sí mismo y no exponerse nuevamente a esas situaciones. Sin embargo, el modelo hegemónico no ha preparado a los hombres para sobreponerse a este tipo de experiencias y se ven más expuestos porque hoy, muchas mujeres ya no se sienten con la obligación de aceptar a un pretendiente o pareja que consideren que no cubre sus expectativas (Barragán, 2003). Actualmente, hombres y mujeres construyen formas de relacionarse, aceptando cambios en los roles y siendo flexibles, alejándose de los supuestos hegemónicos en los que la mujer esperaba la petición y los varones jamás contemplaban una negativa.

Por consiguiente, la forma de afrontar las experiencias de rechazo y/o pérdidas para Sanz (1993), se relaciona con el género y con la historia personal. Para Bustos (2011), los varones viven las pérdidas amorosas de manera más complicada e intensa, suelen reaccionar impulsivamente, hacen actividades que refuerzan la evitación y la negación de lo sucedido como irse a los bares, salir con varias mujeres, entre otras. Del mismo modo, Guevara (2006), encontró que los hombres ante la ruptura de una relación se sintieron solos y usaban estrategias evasivas, aún cuando ellos recibieron apoyo emocional y social durante el proceso por parte de los amigos y familiares.

Lo anterior se relaciona con los procesos de socialización de los varones en cuanto a la expresión de sentimientos. Para muchos hombres es difícil expresar y manejar la tristeza y la desilusión. En algunos casos, los detiene el miedo nuevamente a ser rechazados, como se señaló anteriormente, pues culturalmente no están preparados a lidiar con el hecho de que les digan que "no" y suelen manifestarlo aparentando públicamente lo contrario, pero en lo privado puede manifestarse una depresión (Seidler, 1995), y vivirlo como un proceso muy doloroso, que les lleva años poder recuperarse, tal y como lo experimentó Artemio.

Recuerdo que mi primer noviazgo fue a los 17 años, le dije a Lucía que si un día me decía que sí, yo me iba a desmayar, ella me dijo que quién iba a ir por la ambulancia, entonces yo interpreté que eso, era un sí, y a la semana me dijo 'oye Artemio te voy a pedir de favor ique no digas que soy tu novia!', eso me dolió tanto que estuve desenamorado durante varios años, tenía ganas de tener una relación pero me sentía inseguro, tenía temor a ser rechazado otra vez, eso me duró unos buenos años, y no aprendí a ver los códigos que te envía una mujer.

Los relatos de los participantes contradicen la imagen popular de los varones: "la soledad del hombre es una aventura..." que los coloca en un estado de diversión permanente (Fernández, 2004). Es evidente que los varones experimentan emociones dolorosas ante los rechazos amorosos, mismas que no son reconocidas ni por ellos ni por los otros, porque se espera que oculten la parte vulnerable de sus vidas y tengan todo bajo control.

Estos varones muestran algunas transformaciones en las identidades de género masculino, sin embargo, es importante considerar las formas de participación de la pareja, tanto en el proceso de construcción de la relación, como en los procesos de negociación que tendrán que llevar a cabo durante la trayectoria de vida. Abordar la condición de soltería no es una cuestión individual de él o de ella, sino que incorpora el aspecto relacional de género y los discursos sociales. 


\section{Conclusiones}

Retomando el cuestionamiento inicial: ¿por qué los varones están postergando las ganancias de género que el modelo impone? Se encontró que este esquema se está resquebrajando en varios sentidos: las mujeres han cambiado y requieren varones distintos; muchos están dándose la oportunidad de ser flexibles y cuestionan formas de vida que impone el modelo hegemónico, pero otros sostienen posturas tradicionales en algunos ámbitos de su vida para no perder las ganancias de género, tal como defender su libertad. Algunos sostienen la contradicción de que una relación de pareja los atrapa y atenta contra su libertad (Tena, 2002, Brando, 1999), y al mismo tiempo sigue presente en ellos el deseo de vivir en pareja dentro del esquema normativo de la conyugalidad.

Así pues, su reciente postura de renuencia al modelo tradicional en lo que se refiere a la proveeduría, es un dato relevante, debido a que la situación económica impacta la forma en cómo ahora se relacionan los géneros, sin embargo, este hallazgo invita a indagar más sobre el tema, pues aún no es claro cómo esta renuencia está siendo tomada por las mujeres e incluso por los mismos varones.

Por su parte, el argumento del poco compromiso de los hombres no parece sólo un cliché de las mujeres (Barragán, 2003), aunque los resultados muestran que asumen otras posturas, por ejemplo su reconocimiento a las pocas habilidades en el cortejo y el impacto que ha tenido en su vida la confrontación con el modelo hegemónico.

Finalmente, se considera que la soltería masculina no es un estado de inadaptación, es una condición compleja que conlleva costos sociales, como reconocer el dolor del rechazo de una mujer, lo cual les lleva tiempo para recuperarse, pues hegemónicamente no es posible que una mujer rechace a un hombre, y eso los confronta. Para Barragán (2003), es probable que detrás de la desilusión que hay sobre la vida en pareja, ellos estén deseando una mejor relación. No obstante, es algo que hay que seguir explorando; saber lo que los hombres piensan, valoran, perciben y hacen; las ambigüedades y contradicciones que experimentan, pues al menos, la forma en cómo viven su soltería, refrenda varios aspectos del modelo hegemónico. En relación con esto y con miras a analizar la forma en cómo los hombres participan y se relacionan, mostremos cómo se construye y reproduce el privilegio, y busquemos caminos para la transformación social.

\section{Referencias bibliográficas}

Abarca, H. (1999). Discontinuidades en el modelo hegemónico de masculinidad. Recuperado el día 2 de febrero 2013de http://www. carlosmanzano.net/articulos/abarca.html.

Barragán, A (2003). Soltería: elección o circunstancia. México: Norma.

Baumann, Z. (2001). La vida Líquida. España: Paidós.

Baumbusch J. L. (2004). Unclaimed Treasures: Older Women's Reflections on Lifelong Singlehood. Journal of Women \& Aging. 16 (1-2), 105121.

Bernand, J.A. (2004). La psicología del soltero: entre el mito y la realidad. Barcelona: Desclee De Brouwer.

Blanco, M. (1999). Mujeres profesionistas de clase media: procesos de decisión e inserción laboral. Nueva Antropología, XVI(55) 27-42.

Bourdieu, P. (2004). El baile de los solteros. Francia: Anagrama

Brando, L. (2009). Las mujeres y los hombres que no aman demasiado. La hipermodernidad $y$ las consecuencias de los cambios de roles. España: Difusión Letras.

Bustos, C. (2011). Cuando se acaba el amor: Estrategias de afrontamiento, Duelo por pérdidas amorosas y crecimiento postraumático en estudiantes universitarios. Tesis de grado para la obtención del título de psicólogo clínico. Universidad de San Francisco Quito. En http://repositorio.usfq. edu.ec/bitstream/23000/604/1/99784.pdf consultada el 13 de junio 2012

Byrne,A \&Carr, D.(2005).Caught in the Cultural Lag: The Stigma of Singlehood. Psychological Inquiry, 16, 84-141.

Carmona, N; Farías, E. (2008). La soltería: Una nueva tendencia de la modernidad. Tesis de licenciatura. Universidad Michoacana de San Nicolás de Hidalgo, México. 
Fernández, A. (2004). Solteros, casados y separados. Análisis Feminista, 28(250), 4-9.

Gigy, L, G. (1980). Self Concept of Single Women. Psychology of Women Quarterly (52) 321-340.

Gilder, G. (1974). "Naked Nomads: Unmarried Men in America". Nueva York: Quadrangle/ The New York Times Book Co.

Guevara, E. (2006). Masculinidad, intimidad y políticas públicas. La investigación social: sus aportes, límites y desafíos. En Careaga, G y Cruz. Debates sobre masculinidad. Poder, desarrollo, políticas públicas y ciudadanía. México: UNAM.

Guevara, E. (2010). Cuando el amor se instala en la modernidad: intimidad, masculinidad y jóvenes en México. México: UNAM.

Hunter, H. (2012). Los secretos de los hombres solteros. México: Urano.

Lenard, R. (2007). ¿Cazado? ¡Mejor solterón! México: Novena Estrella.

López, O, M.A (2007). Los nuevos enfoques de la masculinidad y feminidad en una relación de pareja hombre-mujer. Tesis para obtener el título de maestra en psicoterapia humanista. Universidad Vasco de Quiroga. Michoacán, Morelia.

Luco, A. (2001). El sexo imaginario. En Olavarría, J. Hombres: Identidad/es y violencia. Red Masculinidad/es. Chile:FLACSO.

Martínez, B. y Bonilla, A. (2000). Sistema sexo/género, identidades y construcción de la subjetividad. Valencia: Educació. Materials.
Moliner, M. (2001). Diccionario de uso del Español: Versión 2.0. Madrid: Gredos

Olavarría, J . (2001). ¿Hombres a la deriva?. Poder, trabajo y sexo. Santiago de Chile: FLACSO

Rhodes, S; Potash, M.S. (1989). Por qué los hombres no se comprometen? México: Gedisa.

Ruiz, J. (1999). Metodología de la investigación cualitativa. España: Universidad de Deusto.

Salguero, A. (2008). Identidad masculina. Elementos de análisis en el proceso de construcción. México: UNAM.

Sanz, F. (1993). Psicoerotismo femenino y masculino: La integración desde la perspectiva del Reencuentro. En: C. Caruncho y P. Mayobre (Coord.) O reto do presente: Feminismo, Ecoloxia, Pacifismo (pp. 43-53). Universidad de Vigo.

Seidler, V. (1995). Los hombres heterosexuales y su vida emocional. Debate Feminista. 6 (11)

Situmorang, A. (2007). Staying Single in a Married World. Never-married women in Yogyakarta and Medan. Asian Population Studies (3) 287-304.

Tena, O. (2002). Normas morales vinculadas a las prácticas reproductivas de mujeres $y$ varones solteros: trabajo asalariado $y$ religión como dimensiones de análisis. Tesis para obtener el grado de Doctora en Sociología. UNAM.

Valcuende del Rio, J.M; Blanco, J. (2004). Hombres: La construcción cultural de las masculinidades. Madrid: Talasa. 
